\title{
Pragmatic Function of Questioning Act in EFL Classroom Interaction
}

\author{
Hieronimus Canggung Darong ${ }^{1}$, Erna Mena Niman ${ }^{2}$, Yosefina Rosdiana $\mathrm{Su}^{3}$, Fatmawati $^{4}$ \\ \{ronybarera@yahoo.co.id, hieronimusdarong@gmail.com ${ }^{1}$, ernaniman79@gmail.com², \\ Yosephinesu517@gmail ${ }^{3}$, fatmawati1913@gmail.com $\left.{ }^{4}\right\}$ \\ Universitas Katolik Indonesia Santu Paulus ${ }^{1234}$
}

\begin{abstract}
This study was an attempt to analyses the pragmatic functions of EFL teachers' questioning act in their interactions with students. Data were gathered from six purposefully EFL teachers' questions in their interactions with students. Data were transcribed and analyzed following the principle of Conversation Analysis (CA) and Freed's taxonomy (1994) namely external, talk, relational, and expressive functional category. The Conversation Analysis (CA) revealed that most of the questions served more than one purpose ranging from factual information to teacher expressive styles (external, talk, relational and expressive categories). Among the functions found, confirmation and elaboration functions reflecting respectively the talk and relational functional categories appeared at most. Aside from Freed's (1994) category, the speculative function was beneficial to extend the interactions. Then, the functions of questions were not only associated with their pedagogical purposes but also with the pragmatic and social functions depending on the context where they possibly appeared.
\end{abstract}

Keywords: interaction; pragmatic function; questioning act

\section{Introduction}

There have been numerous previous researches in the field concerning with questioning practice in EFL classroom interactions. For instance, focusing on typology, questioning has been acknowledged as the most influential interactive teaching tool to invite student response and provoke students' thinking level. As such, some have claimed that display question invites short student response and aims to check students' understanding on the subject matter. On the other way around, referential question has students to give longer answer and provokes students' deeper thinking level [1]- [10].

Differently, other studies have emphasized the questioning syntactical form. At the level of syntax, teacher questions are characteristically associated and defined by certain grammatical rules such as W-h, Yes-no, declarative, what/how about and tag question. Regardless of the types, the choice of such syntactical constructions in questioning might be of benefit to invite student responses and thinking level [11]- [14]. In addition, the prior studies have indicated that there is a great demand to pay attention on the construction of question in that it determines a proper discourse function of student responses. Thus, they are very useful for various social purposes in teacher-students' interactions.

Along the line of this findings, other previous studies have accentuated the student response and wait-time strategy. Students' responses are mostly influenced by questions types provided 
by teachers. In this respect, asking low order questions, wait-time is unnecessarily offered since quick responses are possibly provided. On the contrary, high order questions necessarily need enough time to think and respond. They allow students to explore and expand their thinking process to respond. Furthermore, in terms of syntactical form, students' responses are restricted as they are given low-order thinking and yes-no questions. On the other way around, whoquestions facilitate more responses from students as they provoke high-order thinking [13], [15]- [20]

Other studies examined teacher questions functioning as a discourse choice marker. Following classroom discourse moves, the studies have proven that an effective strategy of questioning is a great demand to control the structurally transfer of speaking turns or privilege in conversation [21]- [24]. In this context, teacher strategies are closely related to the sequence of talks occurring in classroom interactions.

Pushing the strategy further, other studies have also examined teacher questions functioning as an assessment for learning (AFL) tool [25]- [31]. In this regard, teachers' questions are directions where a teacher and their students realize the strength and weakness of their own and subsequently decide to take an action to reach the learning goals. This is confirmed by [32], [33], [34], [35], [36], [37], [38], and [39] saying that in language classes such as writing and speaking, questioning can be employed in such a way that both teacher and students including peers might be able to provide diagnostic information to reach leaning goals. More importantly, through questioning, a teacher can enhance students learning and, in the meantime, he/she can modify and realign his/her instruction in response to students' needs [37], [40]- [46].

To a great extent, despite the fruitful findings of previous studies, the concerns were only teacher questions functioning as a teaching technique, a linguistic marker, and as an assessment tool (diagnostic) in classroom discourse. However, since questioning is a speech act, it does not only deal with the three functions in question. There is still another function that might be more challenging to examine namely pragmatic function. Therefore, in response to this gap, this study is an attempt to investigate the pragmatic function of teacher questions in EFL classroom interactions.

The profound examination of this function draws on two issues. Firstly, pragmatically, every utterance including a teacher question is produced to carry a certain function or share the force to students as his/her interlocutors. Secondly, having adequate knowledge on questioning pragmatic function would be beneficial in that it provides insights for a teacher to interact and carry the message properly. As such, both should be viewed from a pragmatic point of view and the classroom interaction is the context where teacher-student interactions occur and subsequently brings information about such pragmatic function

\section{Questioning Function}

Teacher questions serve many functions such as a teaching technique, a discourse choice marker, and as an assessment tool. Regarding the former, it can be also divided into two main categories namely motivational and instructional. Motivational function deals with classroom questions which help teachers to engage learners in the lesson and confront their thinking. In real practice, this function can be seen as the teachers draw students' attention back to the lesson and allow others to argue. Meanwhile, instructional function is concerned with classroom questions which help teachers to push the students to learn new material and link it with the previous one. At this point, classroom questions allow the teachers to examine what the students 
know or what they think and how they think about the topic being questioned [1], [4], [47][49].

Along the line of the function aforementioned, question is also used as a discourse choice marker functioning to control an orderly speaking turns or privilege in conversation. In relation to this, the previous research studies have shown that teacher questions can make students involve purposefully in negotiating meaning through explicit correction, repetition, elicitation, clarification, and recast as the interactional features they used [14], [21], [50]- [52].

Meanwhile, the questions might be utilized to vitalize learners thinking and set out to be a guide and a scaffold following the commodity of information exchange in classroom discourse [22]- [24]. As such, teacher questions serve multi-functions or purposes that are seen not only in the context of immediate response but also in the whole discourse moves occurring in interactions.

Aside from teaching technique and conversation management, teacher questions are regarded as a useful tool in assessment (diagnostic tool). In this respect, questioning in classroom interactions which generally has IRF (Initiation, Response, and Feedback) has a significant role to gain data about the current state of students' knowledge which subsequently helps teachers to decide future better instruction. Assessment activity, Assessment for Learning (AFL) in particular, is carried out in some stages namely eliciting, interpreting, and using the information about the students' learning [25], [53]- [59]. To conduct each stage, questions could be utilized to check or inquire their thinking understanding that through their response teacher may realign a future better instruction.

In sum, progress reports in the field have yielded important insights into what and how questioning is. The studies have highlighted teacher questions on instructional context such as recitation and discussion and content. The former deals with teachers' questions functioning to help students to review, check their knowledge and understanding, and provide chances for drill and practice. As such, the teachers dominate the classroom discourse following the norm of IRE. The latter is concerned with the type of questions such as open-ended question functioning to put the students in discussion. While, the content is carried out through factual and procedural questions. Other than those, the prior studies also have emphasized that to facilitate the thinking process, the questions must be associated with the cognitive levels namely remembering, understanding, applying, analyzing, evaluating, and creating. As such, all functions must be constructed in a good and proper wording and syntax in order to communicate what is being asked [5], [11], [19].

However, it is important to note that questioning is a speech act. As teachers raise questions, there must be an effect to the interlocutor. Furthermore, it serves more than one function and its' verbal form alone is not sufficient to carry the function. Therefore, teacher questions must be reliant on pragmatic rules and social norms constructing message to students. In addition, in asking a question, teachers' aims not only to have information or to communicate an event or an experience but also to inflict their influences or to undergo the students' influence based on context (illocutionary acts). Teachers should be able to carry a particular function through their questioning acts. Therefore, teacher questions should be examined pragmatically [60], [61]. In this article, to examine the pragmatic function of teacher questions, the taxonomy of [62] was used. She divides the functions into four categories constituting a wide range of functions from information sought to information conveyed as shown in the following figure. 


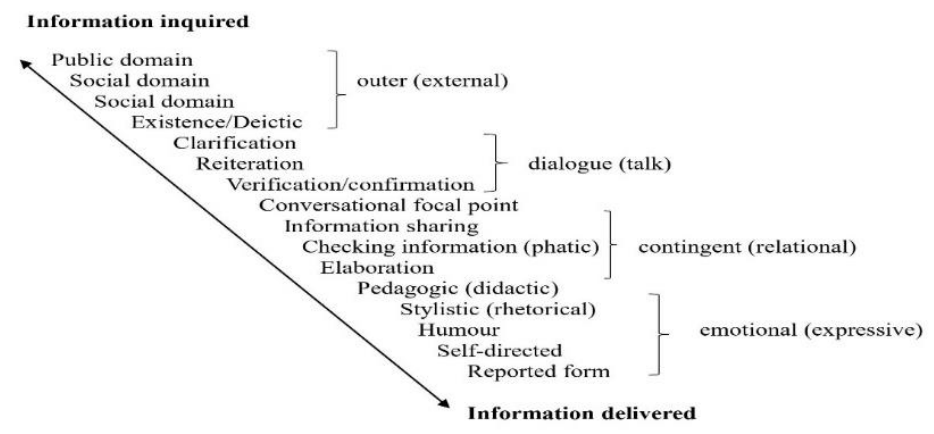

Fig 1. Taxonomy of Question Functions (Freed, 1994)

A cautionary note is necessary regarding the categories presented in the figure1.1. For the sake of analysis, it is useful to conflate the categories into four broader classes, despite the fact that such an integration of functional types obscures certain significant insights which can otherwise be obtained about question functions. In the course of the conversations, the four categories absolutely exist and as being lucid and applicable to classroom discourse.

\section{Method}

For the sake of data, six experienced Indonesian English teachers' classroom interactions of Universitas Negeri Malang were observed and recorded once in 90 minutes. This observational study was a passive observation or non-intrusive observation. In this case, the writer was in the class just to observe and did not interact with both the teachers and students. While observing, note-taking was also necessarily carried out to gain more data.

Conversation Analysis (CA) was utilized to analyses data. The employment of CA to data analysis allows the examination of the pragmatic functions of teachers' questioning with a neutral perspective that is found, what was apparent, during teacher-student interactions. As such, the data were analyzed in some steps. Firstly, all the observed interactions were transcribed which for the most part, were adapted from [63] (Appendix). Secondly, regarding the functions, the transcriptions were carefully coded. Thirdly, data were analyzed in terms of questioning pragmatic function as the concern of the study. As such, the pragmatic functions of questions were analyzed following the taxonomy of [62].

To get the validity of data, triangulation was done to increase the credibility and validity of the findings. As such, it was conducted by cross-checking data, thus assessing the consistency of the information coming from different sources at different or the same times. The data resulting from observation, field notes, and audio recording were compared and verified in such a way that they might be helpful to draw the final conclusion of data analysis. 


\section{Results}

Following the four broad functional categories of [62], Table 1 shows a number of functional types in teachers' questioning act in their classroom interactions. In this respect, the four categories are questions about the externally world, questions about the conversational content or talk, questions about the verbal and social relationship between the teacher and students, and questions used as part of the speaker's expressive style. Sixteen different functions of each category were examined as shown in Table 1. As such, the question-functions range from those which teachers seek factual public information from the students to questionfunctions that convey information from the teachers to the students

Table 1. The distribution of questioning pragmatic function

\begin{tabular}{|c|c|c|c|c|c|c|c|c|c|c|c|c|c|}
\hline Category & $\begin{array}{l}\text { Sub } \\
\text { Function }\end{array}$ & $\mathrm{T} 1$ & TC & $\mathrm{T} 2$ & TC & $\mathrm{T} 3$ & TC & $\mathrm{T} 4$ & $\mathrm{TC}$ & T5 & TC & T6 & $\mathrm{TC}$ \\
\hline \multirow[t]{4}{*}{ External } & Public info & - & \multirow[t]{4}{*}{7} & 2 & \multirow[t]{4}{*}{21} & 14 & \multirow[t]{4}{*}{40} & 3 & \multirow[t]{4}{*}{7} & 2 & \multirow[t]{4}{*}{15} & 4 & \multirow[t]{4}{*}{17} \\
\hline & $\begin{array}{l}\text { Social } \\
\text { invitation }\end{array}$ & 3 & & 6 & & 19 & & 5 & & 13 & & 8 & \\
\hline & Social Info & 4 & & 4 & & 2 & & & & & & 7 & \\
\hline & Deictic & - & & 9 & & 7 & & & & 2 & & 2 & \\
\hline \multirow[t]{3}{*}{ Talk } & Repetition & - & \multirow[t]{3}{*}{321} & - & \multirow[t]{3}{*}{104} & - & \multirow[t]{3}{*}{187} & 1 & \multirow[t]{3}{*}{31} & 2 & \multirow[t]{3}{*}{138} & 2 & \multirow[t]{3}{*}{97} \\
\hline & $\begin{array}{l}\text { Con- } \\
\text { firmation }\end{array}$ & 320 & & 103 & & 168 & & 28 & & 129 & & 97 & \\
\hline & Clarification & 1 & & 1 & & 16 & & 1 & & 6 & & 3 & \\
\hline \multirow{5}{*}{$\begin{array}{l}\mathrm{Re}- \\
\text { lational }\end{array}$} & Elaboration & 155 & \multirow[t]{5}{*}{154} & 58 & \multirow[t]{5}{*}{60} & 85 & \multirow[t]{5}{*}{90} & 27 & \multirow[t]{5}{*}{28} & 76 & \multirow[t]{5}{*}{82} & 57 & \multirow[t]{4}{*}{67} \\
\hline & Phatic & 8 & & 2 & & 9 & & - & & 6 & & 3 & \\
\hline & Shared info & 1 & & - & & - & & - & & - & & 3 & \\
\hline & \multirow{2}{*}{$\begin{array}{l}\text { Conversation } \\
\text { al focus }\end{array}$} & \multirow[t]{2}{*}{-} & & 1 & & - & & - & & - & & - & \\
\hline & & & & & & & & & & & & & \multirow[t]{6}{*}{6} \\
\hline \multirow{5}{*}{$\begin{array}{l}\text { Ex- } \\
\text { pressive }\end{array}$} & Humor & 3 & \multirow[t]{3}{*}{3} & 4 & \multirow[t]{3}{*}{4} & 1 & \multirow[t]{3}{*}{9} & - & \multirow[t]{3}{*}{-} & - & \multirow[t]{3}{*}{6} & - & \\
\hline & Self-directed & - & & - & & 2 & & - & & - & & 2 & \\
\hline & Didactic & - & & - & & 4 & & - & & 6 & & 4 & \\
\hline & Rhetorical & - & - & - & - & - & - & - & - & - & - & - & \\
\hline & $\begin{array}{l}\text { Reported } \\
\text { speech }\end{array}$ & - & - & - & - & - & - & - & - & - & - & - & \\
\hline $\begin{array}{l}\text { Spe- } \\
\text { culative }\end{array}$ & & 17 & & 2 & & 5 & & - & & 68 & & 2 & 94 \\
\hline
\end{tabular}

The data indicate that the teachers mostly confirmed students' knowledge and understanding, elaborated on the topic being discussed. These two functions reflect the categories of talk and relational which existed more during the interactions. However, they were supported by other functions following the conversation moves. In addition, out of the category of [62], speculative function was found in teachers' interactions. This function could maintain the interactions in the classroom and the students were generally provoked to elaborate their ideas using their concepts and imagination. Through this question function, students learn how to speculate in response to the teacher modelling open-ended questions, students can learn to think aloud, imagine, and explore new ideas. 


\section{Discussion}

Looking at the data (Table 1), it became clear that questions were varied and had a number of different pragmatic functions following the context where they occurred. When they were examined in context, questions were multi-functional and served several purposes. In isolation, a teacher's question might elicit factual social information, but which, in context, was identified to elaborate some previous contributions. In this respect, the important connection among them might be revealed after a consideration of the type of information that the question implicitly referred to and the particular conversational contexts when uttered. The following extract that was taken from T1's interactions confirms that the question serves multi-functions.

\section{Extract 1}

$T$ : Can you tell me why you are here?

S1 : I am here for learning assessment.

$T$ : Right. What do you think? Does she answer my question?

S2 : Silent ().

$T:$ I have no idea why she could answer my question $\downarrow$ Could you say something please?

S2 : She could answer your question because she knows the purpose.

$T$ : OK. Absolutely right. There must be a purpose there $\downarrow$ It is a crucial feature of communicative assessment. I am doubtful if you consider that one.

The extract shows how the teacher's questions served more than one function. The question "does she answer my question?" functioned as confirmation regarding the prior contributions. However, in the meantime, this question belongs to the category of expressive that is a didactic function through which the teacher taught something for the students. Likely, the question "could you say something please?" was a request and categorized as a social invitation which belongs to the external sort or category. Yet, at the same time could be an effort to elaborate the topic. In this regard, both categories of functional talk and relational occupied by means of the same question.

The data (Table 1) confirms that the teachers mostly confirmed students' knowledge and understanding and elaborated on the topic being discussed (Extract 1). Although these two top question functions varied in number among teachers, they dominated other questioning functions. As can be seen in the table, during the process of interactions, the teachers mostly asked questions functioning to confirm student's understanding. They existed respectively 320 (T1), 103 (T2), 168 (T3), 28 (T4), 129 (T5), and 97 (T6). While, the questions functioning to elaborate the topic came at the second position and occurred respectively, in total 155 (T1), 58 (T2), 85 (T3), 27 (T4), 76 (T5), and 57 (T6).

The table also shows that other clarification functions appeared differently in all teachers. Even though they were different in terms of the number, once in T1, T2, and T4, 16 times in T3, 6 times in T5 and 3 times in T6, the clarification function was concerned with additional information related to the content of other speaker's previous utterance occurring the immediate conversation. Extract 2 which was taken from T3's interactions delineates this function.

\section{Extract 2}

$S$ : I have read a book $\uparrow$. a book. it is the book of Silindile Mkhize

$T$ : Silindile Mkhize?

$S$ : Yes. So it is what is it..umm. Power of words. Very interesting.

$T$ : Power of words? Interesting?

$S$ : Ya.ya. The book is very interesting to me. The book is about.

$T$ : Louder, please! 
The questions " Silindile Mkhize?" and "Power of words?" are clarification. This question linking to student previous contributions from the immediate conversation looks for additional information. In other words, the question itself is often a repetition or paraphrase of some fragments of the earlier utterance but the question seeks new details or information for the previous utterance. The information was regarded by the teacher as if it were still new information.

In order to keep the conversation meaningful, questions assisting the teachers to identify that the students were present at or attending the information exchange in the interactions and/or were conscious of the relevant background information were posed by the teachers in this study (except T4). As seen in Table 4.1, this phatic function occurred 8 times in T1, twice in T2, 9 times in T3, 6 times in T5, and 3 times in T6. Extract 3 which was taken from T5's interactions illustrates the occurrence of this function.

\section{Extract 3}

$T$ : Do you think you will take this as your proposal seminar?

$S:$ :Yes.

$T$ : Ya..you take this as your proposal seminar. You know what I mean? So.. you are supposed to be aware of citation. The way how to cite the text for references. So.. you have to take TPS. Ya个

$S$ : This semester.

$T$ : Sorry.. this semester?

The extract shows how the teacher checked that the students are following the information exchange in the conversation and/or is conscious of the pertinent background information by questioning "you know what I mean?". As such, the questions were constructed in such a way that the teacher had a willingness to know whether the students were following her explanation about ways of citation or not. Different from confirmation function which the purpose was to check students' understanding of the topic being talked, this function focused on information exchange at the moment of speaking or the immediate occurring talk conditions.

Social invitation functions also appeared in all the teachers' interactions resulting from the topic elaboration. It was found that the teachers' questions functioned to invite students to do an action occurred differently. Respectively, there were 3 for T1, 6 for T2, 19 for T3, 5 for T4, 13 for T5 and 8 times for T6. As the nature of this function is to invite or request information, it involves the physical participation of the students, as shown in the extract 4 (taken from T2's interactions).

\section{Extract 4}

$T$ : Can you please give one sentence that fits the structure?

$S$ : She made a cake for her mother.

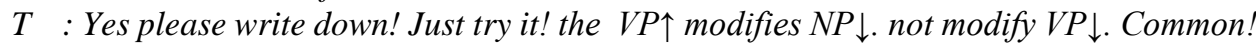

$S:$ (writing the sentence)

$T$ : Yes that's possible. Yes. That's possible. One more. Common $\uparrow$ One of you please! Santi please!

The question "can you please give one sentence that fits the structure?" is a social invitation wherein physical participation was required. In this case, such function is often delineated as indirect speech acts and accepted as invitations or offers by way of conventional implicature [23], [62], [64], [65]. Differently, Social information function appeared only in 
some teachers that were 4 times in $\mathrm{T} 1$ and T2, twice in $\mathrm{T} 3$ and 7 times in T6. Extract 5 illustrates this function in the interactions of T6 and his students

\section{Extract 5}

$T \quad$ : He will be waiting for you outside the school. Future progressive. He is waiting for you outside the school. Present continuous. Have you ever experienced this? (Laughing)

Ss : Yes (laughing)

$T$ : Will be waiting or are waiting?

$S$ : It depends on Sir.

$T$ : (laughing)

The question "have you ever experienced this?" asked for new private domain information of a factual and specific nature. Questions in this category were applicable or were relevant to the persons (teachers), his lives, and events with which they are acquainted with. In terms of accessibility, private domain information is frequently more than the public domain. Aside from the functions mentioned, repetition function also appeared. It occurred (except T1, T2, and T3) once in $\mathrm{T} 4$ and twice in $\mathrm{T} 5$ and $\mathrm{T} 6$. This function dealt with the literal repetition of a previous contribution made by the students. In this case, the actual signal, not of the semantic content of the previous contribution was the intention of such repetition question

\section{Extract 6}

$T$ : So it refers to the body. Whose body is it? It refers to the human body? Which body in the story that related to the temple of Holy Ghost story here?

$S$ : The body as stated in the story the cousins having two sexes.

$T$ : Sorry?

$S:$ In the story.. there are two cousins there and mentions that they represent the temple of the Holy Ghost.

The question "sorry?", in this case, virtually identical nature of the utterances coming before and after the questions would be of benefit in identifying it as repetition. Meanwhile, the absence of this function in some teachers was due to the teacher's effort to manage the flow of conversation. Public information function in this corpus was found from the questions which asked for public domain information. The transcript shows that, except T1, all participants which successively appeared twice in T2, 14 times in T3, 3 times in T4, twice in T5 and 4 times in T6, carried the function to enlarge and lengthen the talk by placing the students' mind to the external domain. Such questions were about the external world and requested new factual information as shown in the extract 7 (T3's interactions).

\section{Extract 7}

$S$ : The boat just gone. There is no..there is

$T$ : So, there is no clue where about the boat.

$S$ : But it is not ...It is not gone really there is a...

$T$ : OK... there were some remains of the boat. like the roof $\uparrow$. the plan whatever. So, but there is no explanation where the boat was gone.

$T:$ I think I know the location. Can you guess the location in the pacific area? What is it? Is there in the pyramid triangle?

$S$ : There was no explanation about the specific area but...

$T$ :Ya..ya ..OK. Can you choose a person/ to give a question, comment or whatever? 
The questions "can you guess the location in the pacific area?", "What is it?", is there in the pyramid triangle?" were posed to require the students to associate the topic to the external domain following teachers' wish. To a certain circumstance, this might deviate from the course as it was outlined following the classroom discourse moves. As such, the function might be absent as found in $\mathrm{T} 2$, as the focus of discussion was in the exercises which subsequently lead to a monotonous discussion.

The questions were also posed to get new or related factual information about the immediate physical environment. The teachers' questions (except T1 and T4) carrying this function occurred 9 times in T2, 7 times in T3, twice in T 5 and T6. Here, the information being employed is generally physically accessible

\section{Extract 8}

$T$ : OK. Question for everything? Finish?

$S$ : Here I should get...(())

$T$ : What is that?..(pointing to the paper) Wow...Sorry, I am wrong.

$S:$ I should get... (O)

$T:$ :Oh really $\uparrow$ OK. Put it here! I'll correct it later.

$S$ : Thank you Mom.

$T$ : Any time.

This deictic function of the question "What is that?" occurred as the teacher were about to clarify and confirm even elaborate on the topic being talked relying on physical things as pointing to the paper in the above extract. Meanwhile, another function was found as the teachers posed the question as pre-announcements [66]. This took place as the teachers had the students to the informational content contained in what the teacher was about to utter or about the direction the conversation was about to deal with. Extract 9 that was taken from T2's interactions present such function.

\section{Extract 9}

$T$ : OK. Now.. before we discuss why $\uparrow$ Let me tell you that for number one this is correct number 2 and number 3 is wrong. However $\uparrow .$. I need these mistakes. Why? Because I need to show you that when you create a sentence it is not enough to clarify by its lexicon but you have to look the structure as a whole. You have to consider the structure.

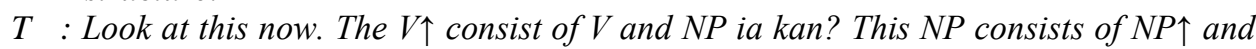
$V P$.

$S \quad:$ ohhhh...

This conversational focus function, "However $\uparrow .$. I need these mistakes., Why?" which in fact, existed only once that is in T2, lead the teacher about what to utter and the students to focus on what was being conversed. The table has also shown that in two teachers' interactions, questions functioning as sharing information or knowledge appeared. The data (Table 1) confirm that the questions (once in T1 and 3 times in T6) were totally provided with the purpose of establishing knowledge or reactions, the existence of mutual or shared information. Extract 10, taken from T6's interactions, delineates such function to his students.

\section{Extract 10}

$T \quad$ : Do you know this story about this? During the reign of Kubalaikan. Who is Kubalaikan? Kubalaikan? Hello $\uparrow$ He is from China. He invaded Indonesia. So, you should use the past tense. 
$T \quad$ :In 1825. The story of Diponegoro, right $\uparrow$. Read the story? in 1825? What happened? Dipenegoro attacked Batavia. Do you know what happened in 1830? He was captured. So.. Diponegoro attacked Batavia. Past tense.

Meanwhile, the absence in the other teachers' interactions occurred as they relied more on students' source (data) during the session, which in turn, confirmation and elaboration function had to be there. Besides, the teaching activities, move of commodity exchange, and topics were identified as the causes. Sharing amusement was another question function found in this study. This function respectively occurred 3 times in T1, 4 times in T2, and once in T3. Extract 11 which was taken from T1's interactions illustrates the occurrence of this function.

\section{Extract 11}

$T$ : Is it an action?

Ss : Yes.

$T$ : Is it production?

Ss : Yes.

$T$ : Why are you standing here?

Ss : (laughing)

$T \quad$ : What does this mean by why are you standing here? Do you think I tell her to sit down?

Ss : Yes.

$T$ : Which function?

Ss : Context.

$T:$ context $\uparrow$

Ss : Meaning.

$T$ : This context means asking her to sit down. Right. it is meaning.

The question' why are you standing here?" was expressed to the students as part of the teacher's expressive style. Although the teachers knew the answers, as didactic and some rhetorical questions, the exchange sought was not about information but was a shared amusement. In this context, the teacher question expressing information from an unexpected point of view (no expectation for the responses) and depending on the teacher's sense of humour served the basis of its occurrence.

In certain circumstance, the teacher asked questions functioning to seek information which only can be supplied by the teacher him/herself. As shown in Table 4, two teachers (T3 and T 6) employed this function twice for each. The function which is the so-called self-directed function orients the students toward the teachers in the process as shown in extract 12 (T6's interactions).

\section{Extract 12}

$T \quad$ : This occurs in number two. An expression. Remember. that expression that is by the year 2020. when we talked about the time here. we have future perfect. In 2025. what will we have? Arema will win the match again.

Ss : (laughing)

The question "what will we have?" truly reflects the teacher's expressive style in the speaking. As such, the question needs no response from the students and the teacher himself was the one who supplied the answer. Shortly, this was another form of teacher's expressive style in questioning during his interaction with the students. 
The questions leading the students to information which the teacher already knows; the teacher is asking about certain information in order to teach the students something appeared 4 times in T3, 6 times in T5 and 4 times in T6. Extract 13 that was taken from T6 delineates this function

\section{Extract 13}

$T \quad$ : Do you understand the explanation? Do their speaking or explanation use the rule of parallelism? OK. What is the correct spelling of companion? What does it mean? OK. Open your dictionary!

$S$ : Yes sir.

$T \quad$ : Now. Write on the book! F... l... o... u... r. this is pronunciation ya $\uparrow$ How do you pronounce it?

$S$ : Flauer.

$T$ :OK. Now. write again! F... l... o... w... e... r. How do you pronounce it?

$S$ : Flauer.

$T$ : OK. The two words are spelled differently. but they are pronounced the same.

These didactic functions are different from shared information function. The focus of sharing information is the establishment of the existence of mutual or shared information, knowledge or reactions. The questions posed refer to the students to information which the teacher already knows. Conversely, the didactic function is concerned with teachers' ways or motives of delivering something new to the students such as "what is the correct spelling of companion? How do you pronounce it? Shortly, there must be something to teach through questioning.

Last but not least, the analysis indicates that by far the common function of questions fits the four functional categories that are external, talk, relational and expressive. However, out of [62]'s category, the researcher found a speculative function of questions employed by the teachers. As seen in Table 1, this function was mostly carried by teacher 5 (68 times) and followed by the T1 (17 times). Yet, in some participants, such speculative function occupied less (twice in T2 and T6 and 5 times in T3) and were absent in T 4. This occurred as the prioritizing of teaching (delivery and content) over learning (understanding). Similar to other functions, the questions carried speculative functions discursively associated with preceding and following contributions and the goals of the classroom discourse as shown in extracts 14 and 15 which were respectively taken from $\mathrm{T} 1$ and $\mathrm{T} 3$.

\section{Extract 14}

$T$ : Now have you yourself ever experienced a very serious storm in your life?

$S$ : No..and I will not.

$T$ : You will not. How can be you so sure?

$T \quad$ : But what may have cause ((congenital)) rain or what may have cause of that being amount of rainfall or abnormal amount of rainfall?

$T \quad$ : When you are reading this, what did this reminding you of? When I read this, I remind the tsunami in Aceh at that time right $\uparrow$.

\section{Extract 15}

$T$ : What about in doctor's room? What are they?

$S$ : Doctor and patient.

$T$ : OK. That's obvious.

$T \quad$ : What are you supposed to do? You cannot just say. Right. Paraphrase $\uparrow$ without any context? No. You have to add $\uparrow$ the context. 
$T$ : What else? Beside role play? Beginning with D. This is a part of the course you have.

$S$ : Drama.

$T$ :OK. In your company for example. How about the role? or when you are concerning with job application. What about the role?

The teachers' speculative questions potentially provoke a higher level of cognitive response and genuinely have students' speculative responses and even left unanswered. In these cases, the teachers raised questions to invite a response with no predetermined answer, often opinions, hypotheses, imaginings, and ideas. Although, as the name suggests, they invited speculative response, on the basis of their role, they constituted important roles, like other functions, in classroom discourse.

By and large, it was obvious that questions were functioning in a number of different ways and that their various functions should be carefully examined within the context of the particular talk situation in which they appeared. The relation among them became clear as they were only after the examination of the type of information that the questions concerned and conversational contexts where it appears. Furthermore, it is worth restating that a question serves more than one purpose. Yet, the main function is discerned from the context in which question appears. The context preceding and following each question should be carefully seen to come at the specific function of teacher question.

Previous research studies have confirmed that the functions of teacher questioning allow the teacher to examine students' understanding (diagnostic/assessment tool), encourage students to have something new, challenge their thinking and link it to the previous knowledge (instructional or teaching technique), and engage learners in the conversation (discourse). The functions in question reflect teacher's ways to utilize questions and put their students actively, through their responses in meaning negotiation process or sequence of talk [1], [3], [5], [16], [19], [47], [50]- [52], [67].

However, in this study, the questions were posed to understand the variety of information and that they provided the teachers with the means to know about the external world, the students' life, emotions, shared events, experiences and about the conversation itself. Yet, there were some questions, which in fact, provided no information at all. These questions were about to get the students to deal with a certain point in the conversation or to discern that the students were already present at some certain points. Besides, there were some questions posed to which the teachers had the answer or for which left unanswered (no answer). In these cases, the information was not the concern and was not being sought or left an unexpected response from the students. Such questions were, instead, the teachers' expressive choice and only delivered certain information to them. Although they did not completely fill the functions purposed by Freed, overall, the question acts examined in this study ranged from the most narrowly factual questions raised to the questions showing an individual teacher's expressive style.

More specifically, the question functions found in this study cover four broad functional categories namely questions about the external domain consisting of public information, social information, social invitation, and deictic information questions, the conversational content or talk comprising clarification questions, repetition questions, and confirmation questions, the verbal and social relation between the teacher and students encompassing conversational focus, shared information, phatic information questions and questions which ask for elaboration, and questions used as part of the teachers' expressive style embodying didactic questions, questions used for humor, and self-directed questions.

Moving ahead to another function, a speculative function occupied and constituted significantly to the classroom talks. Although speculative questions which invited opinions, 
hypotheses and imaginings, or process questions, provoking children to articulate their understanding [68] appeared less than the other two dominant functions (confirmation and elaboration) and were posed only by some teachers, they were beneficial to extend the interactions. This may be due to the focus of teaching (delivery and content) over learning (understanding). Besides, although on a certain occasion, the answer to these questions was made by the teachers themselves, they, in fact, potentially provoked a high level of cognitive response.

Thus, the function of questions, as found in this study, was not only regarded and associated with their pedagogical purposes embodying question as a teaching technique [1], [2], [4], [5], [49], as a discourse marker [14], [20]- [24], [50]-[52] and as an assessment tool [26][30], [38], [69] but also with the pragmatic and social function depending on the context where and how they possibly appeared. As such, to strengthen [8], [20], [21], [23], [70], [71] saying that the interpretation of the intended context is of benefit in revealing the teacher questions, the commodity exchange in classroom discourse moves is another aspect to deal with questioning function in classroom interactions

\section{Conclusion}

It is obvious that the question serves multi-functions in context covering four functional categories incorporating external, talk, relational and expressive category. Among the four, talk and relational functional categories were at the top rank. While the speculative function which is newly found in this study appeared as the teachers have the students focusing on their imagination and hypothesis following the discourse moves in the interactions.

Given the important role in classroom interactions, it seems reasonable to suggest that the teacher should not only concerned with the functions of questioning as a teaching technique, a discourse marker, and an assessment tool (diagnostic) but also with the pragmatic function. This is not to say that teachers' awareness of the three functions is not helpful. Purposeful awareness of pragmatic function as found in this study effectively leads both teacher and students to conduct their interactions that linguistically meet and contextually touched.

This present study suffered from limitations that should be taken into account for further studies. Since the scope of the study was only pragmatic function teachers' questioning acts, the investigation of other aspects of questioning practice such as types and forms along with their convergence and divergence might be more potential in further studies. In addition, the inclusion of other variables such as students' thinking level, topic familiarity, and subject matter might be more challenging to cope with.

\section{Acknowledgment}

Many thanks to the teachers and students of the English department in Universitas Negeri Malang for so gracefully welcoming us in their classroom as observers, thus making this study possible. This research was supported by the UKI Santu Paulus Ruteng and no potential conflict of interest was reported by the authors

\section{References}

[1] M. Engin, "Questioning to Scaffold : An Exploration of Questions in Pre-Service Teacher Training Feedback Sessions," Eur. J. Teach. Educ., vol. 36, no. 1, pp. 39-54, 2013.

[2] T. S. C. Farrell and J. Ives, "Exploring Teacher Beliefs and Classroom Practices through Reflective Practice : A Case study,” Lang. Teach. Res., vol. 19, no. 5, pp. 594-610, 2015. 
[3] L. Ngoc, K. Pham, and M. O. Hamid, "Beginning EFL Teachers' Beliefs about Quality Questions and Their Questioning Practices," Teach. Dev. An Int. J. Teach. Prof. Dev., vol. 17, no. 2, pp. 246264, 2013.

[4] J. B. Hill, "Questioning Techniques : A Study of Instructional Practice Questioning Techniques : A Study of Instructional Practice," Peabody J. Educ., vol. 91, no. 5, pp. 660-671, 2016.

[5] B. M. Wright, "Display and Referential Questions : Effects on Student Responses," Nord. J. English Stud. 15(4)160-189., vol. 15, no. 4, pp. 160-189, 2016.

[6] A. Rido, "What Do You See Here from This Picture?: Questioning Strategies of Master Teachers Indonesian Vocational English Classroom,” TEFLIN J., vol. 28, no. 2, pp. 193-211, 2017.

[7] Sujariati, Q. Rahman, and M. Mahmud, "English Teacher's Questioning Strategies in EFL Classroom at SMAN 1 Bontomarannu," ELT Worldw., vol. 3, no. 1, pp. 1-15, 2016.

[8] H. C. Darong, A. E. Kadarisman, Y. Basthomi, N. Suryati, M. Hidayati, and E. . Niman, "What Aspects of Questions Do Teachers Give Attention To?," Int. J. Innov. Creat. Chang., vol. 10, no. 11, pp. 191-208, 2020.

[9] S. Harvey and R. L. Light, "Questioning for Learning in Game-based Approaches to Teaching and Coaching,” Asia-Pacific J. Heal. Sport Phys. Educ., vol. 6, no. 2, pp. 175-190, 2015.

[10] G. Hu and Y. Duan, "Questioning and Responding in the Classroom : A Cross-Disciplinary Study of the Effects of Instructional Mediums in Academic Subjects at a Chinese University,” Int. J. Biling. Educ. Biling., vol. 22, no. 1, pp. 1-20, 2018.

[11] S. Durrleman and J. Franck, "Syntactic Complexity in the Comprehension of Wh- Questions and Relative Clauses in Typical Language Development and Autism," Appl. Psycholinguist., vol. 37, no. 6, pp. 1501-1527, 2016.

[12] W. Ozuem and G. Lancaster, "Questioning: A Path to Student Learning Experience," Educ. + Train., vol. 57, no. 5, pp. 474-491, 2015.

[13] H. Z. Waring, E. Reddington, D. Yu, and I. Clemente, "Going General : Responding to Yes - No Questions in Informational Webinars for Prospective Grant Applicants," Discourse Commun., vol. 12, no. 3, pp. 307-327, 2018.

[14] A. S. Salerno and A. K. Kibler, "Questions They Ask : Considering Teacher-inquiry Questions Posed by Pre-service English Teachers," Educ. Action Res., vol. 23, no. 3, pp. 399-415, 2015.

[15] S. Kao, G. Carkin, and L. Hsu, "Questioning Techniques for Promoting Language Learning with Students of Limited L2 Oral Proficiency in a Drama- Oriented Language Classroom," Res. Drama Educ. J. Appl. Theatr. Perform., vol. 16, no. 4, pp. 489-515, 2011.

[16] T. Tofade, J. Elsner, and S. T. Haines, "Best Practice Strategies for Effective Use of Questions as a Teaching Tool," Am. J. ofPharmaceutical Educ., vol. 77, no. 7, pp. 1-9, 2013.

[17] C. M. Gilson, C. A. Little, A. N. Ruegg, and M. Bruce-davis, "An Investigation of Elementary Teachers ' Use of Follow-Up Questions for Students at Different Reading Levels," J. Adv. Acad., vol. 25, no. 2, pp. 101-128, 2014.

[18] Y. P. Robitaille and F. Lauderdale, "Teachers' Experiences Relative to Successful Questioning and Discussion Techniques,” Am. Int. J. Contemp. Res., vol. 5, no. 1, pp. 7-16, 2015.

[19] E. Tavakoli and M. Davoudi, "Question Generation Behavior of Reflective Teachers," Reflective Pract. Int. Multidiscip. Perspect., vol. 17, no. 4, pp. 415-429, 2016.

[20] R. L. Walsh and K. A. Hodge, "Are we asking the Right Questions? An Analysis of Research on the Effect of Teachers ' Questioning on Children' s Language during Shared Book Reading with Young Children,” J. Early Child. Lit., vol. 18, no. 2, pp. 264-294, 2018.

[21] A. Zemel and T. Koschmann, "Pursuing a Question: Reinitiating IRE Sequences as a Method of Instruction,” J. Pragmat., vol. 43, no. 2, pp. 475-488, 2011.

[22] M. P. Boyd, "Relations Between Teacher Questioning and Student Talk in One Elementary ELL Classroom," J. Lit. Res., vol. 47, no. 3, pp. 370-404, 2015.

[23] S. Yazdanfar and A. Bonyadi, "Request Strategies in Everyday Interactions of Persian and English Speakers," SAGE Open, no. October-December, pp. 1-11, 2016.

[24] Z. Tajeddin and M. Pezeshki, "Acquisition of Politeness Markers in an EFL Context : Impact of Input Enhancement and Output Tasks,” RELC J., vol. 45, no. 3, pp. 269-286, 2014. 
[25] P. J. Black and D. Wiliam, "Developing the Theory of Formative Assessment," Educ Asse Eval Acc, vol. 21, no. 5, pp. 5-29, 2009.

[26] F. Gattullo, "Formative assessment in ELT primary (elementary) classrooms: an Italian case study," Lang. Test., vol. 17, no. 2, pp. 278-288, 2000.

[27] I. A. S. Widiastuti and A. Saukah, "Formative Assessment in EFL Classroom Practices," Bhs. dan Seni, vol. 45, no. 1, pp. 50-63, 2017.

[28] Milawati, "Teacher Questioning as a Formative Assessment Strategy in EFL Context," JELTL (Journal English Lang. Teach. Linguist., vol. 2, no. 2, pp. 117-134, 2017.

[29] Y. Jiang, "Exploring Teacher Questioning as a Formative Assessment Strategy," RELC J., vol. 45, no. 3, pp. 1-18, 2014.

[30] M. Heritage and J. Heritage, “Applied Measurement in Education Teacher Questioning: The Epicenter of Instruction and Assessment Teacher Questioning," Appl. Meas. Educ., vol. 26, no. 3, pp. 176-190, 2013.

[31] R. C. Pianta, "Teacher - Student Interactions : Measurement , Impacts , Improvement , and Policy," Policy Insights from Behav. Brain Sci., vol. 3, no. 1, pp. 98-105, 2016.

[32] X. Huang and X. Hu, "Teachers' and Students' Perceptions of Classroom Activities Commonly Used in English Speaking Classes," High. Educ. Stud., vol. 6, no. 1, pp. 87-100, 2016.

[33] S. Swaffield, "Getting to the Heart of Authentic Assessment for Learning," Assess. Educ. Princ. Policy Pract., vol. 18, no. 4, pp. 433-449, 2011.

[34] J. Herman, E. Osmundson, Y. Dai, C. Ringstaff, and M. Timms, "Investigating the Dynamics of Formative Assessment: Relationships between Teacher Knowledge, Assessment Practice and Learning," Assess. Educ. Princ. Policy Pract., vol. 23, no. 3, pp. 344-367, 2015.

[35] R. Lam, "Enacting Feedback Utilization from a Task-Specific Perspective," Curric. J. ISSN, vol. 28, no. 2, pp. 266-282, 2016.

[36] I. Lee, "Formative Assessment in EFL Writing: An Exploratory Case Study," Chang. English, vol. 18, no. 1, pp. 99-111, 2011.

[37] I. Lee, P. Mak, and A. Burns, "EFL teachers ' attempts at feedback innovation in the writing classroom," 2015.

[38] A. Şimşek and S. I. K. Gönen, "Raising Awareness of EFL Teachers on Question Types and Pedagogical Goals: An Analysis through Classroom Modes,” Lang. Teach. Educ. Res., vol. 3, no. 1, pp. 56-75, 2020.

[39] S. F. Obeiah and R. F. Bataineh, "The Effect of Portfolio-Based Assessment on Jordanian EFL Learners' Writing Performance,” Bellaterra J. Teach. Learn. Lang. Lit., vol. 9, no. 1, pp. 32-46, 2016.

[40] H. Nassaji, "Anniversary Article Interactional Feedback in Second Language Teaching and Learning: A Synthesis and Analysis of Current Research," Lang. Teach. Res., vol. 20, no. 4, pp. 535-562, 2016.

[41] J. Park, "Effectiveness of Teacher and Peer Feedback: Through the Lens of Korean Tertiary Writing Classroom," J. Asia TEFL, vol. 15, no. 2, pp. 429-444, 2018.

[42] N. Sritrakarn, “A Comparison of Teacher's and Senior Students 'Feedback: Student,” J. Asia TEFL, vol. 15, no. 2, pp. 329-348, 2018.

[43] S.-Y. Choi and S. Li, "Corrective Feedback and Learner Uptake in a Child ESOL Classroom," RELC J., vol. 43, no. 3, pp. $331-351,2012$.

[44] M. Ganapathy, D. Ai, L. I. N. Tan, and J. Phan, "Impact of Written Corrective Feedback on Malaysian ESL Secondary Students 'Writing Performance," 3L Southeast Asian J. English Lang. Stud., vol. 26, no. 3, pp. 139-153, 2020.

[45] A. E. Fadilah, M. Anugerahwati, and J. A. Prayogo, "EFL Students' Preferences for Oral Corrective Feedback in Speaking Instruction," J. Pendidik. Hum., vol. 5, no. 2, pp. 76-87, 2017.

[46] A. F. Laeli and S. Setiawan, "Oral Corrective Feedback in Speaking Class: Its Frequency, Students' Perceptions, and Preference,” Expo. J. Pendidik. Bhs. Ingg., vol. 8, no. 2, pp. 257-269, 2019.

[47] S. H. Qashoa, "Effects of Teacher Question Types and Syntactic Sructures on EFL Classroom Iinteraction,” Int. J. Soc. Sci., vol. 7, no. 1, pp. 52-62, 2013.

[48] T. S. C. Farrell and V. Mom, "Exploring Teacher Questions through Reflective Practice," Reflective Pract. Int. Multidiscip. Perspect., vol. 16, no. 6, pp. 849-865, 2015. 
[49] G. Hu and Y. Duan, "Questioning and Responding in the Classroom : A Cross-Disciplinary Study of the Effects of Instructional Mediums in Academic Subjects at a Chinese University," Int. J. Biling. Educ. Biling., vol. 22, no. 1, pp. 1-20, 2018.

[50] J. Eckerth, "Nogitiated Interaction in the L2 Classroom," Lang. Teach., vol. 42, no. 1, pp. 109-130, 2009.

[51] G. Palma, "A Classroom View of Negotiation of Meaning with EFL Adult Mexican Pupils," 2014.

[52] K. Saito and K. Hanzawa, "The Role of Input in Second Language Oral Ability Development in Foreign Language Classrooms : A Longitudinal Study," Lang. Teach. Res., vol. 22, no. 4, pp. 398417, 2016.

[53] I. Clark, "Formative Assessment : ' There is Nothing So Practical As a Good Theory," Aust. J. Educ., vol. 54, no. 3, pp. 341-352, 2010.

[54] S. Ketabi, "Classroom and Formative Assessment in Second/Foreign Language Teaching and Learning," Theory Pract. Lang. Stud., vol. 4, no. 2, pp. 435-440, 2014.

[55] A. W. Gotwals and D. Birmingham, "Eliciting, Identifying, Interpreting, and Responding to Students 'Ideas: Teacher Candidates ' Growth in Formative Assessment Practices," Res Sci Educ, vol. 46, no. 3, pp. 365-388, 2015.

[56] F. Van Der Kleij, J. A. Vermeulen, H. Inholland, K. Schildkamp, and T. J. H. M. Eggen, "Integrating Data-based Decision Making, Assessment for Learning and Diagnostic Testing in Formative Assessment," Assess. Educ. Princ. Policy Pract., vol. 22, no. 3, pp. 324-343, 2015.

[57] H. Robiasih and T. Lestari, "Formative Assessment Performed by High School Teachers in the Pandemic Era," Loquen English Stud. J., vol. 13, no. 2, pp. 80-87, 2020.

[58] E. C. Wylie, "Observing Formative Assessment Practice: Learning Lessons Through Validation," Educ. Assess., vol. 25, no. 4, pp. 1-8, 2020.

[59] M. Birenbaum et al., "International Trends in the Implementation of Assessment for Learning: Implications for Policy and Practice,” Policy Futur. Educ., vol. 13, no. 1, pp. 117-140, 2015.

[60] T. S. Yap and S. Pillai, "Intonation Patterns of Questions in Malaysian English Intonation Patterns of Questions in Malaysian English," Asian Englishes, vol. 20, no. 3, pp. 1-14, 2017.

[61] L. Sundh, "The function of Teacher Questions in EFL Classroom Activities in Cambodia: A conversation Analytic Study,” Dep. English Individ. Res. Proj., pp. 1-32, 2017.

[62] A. F. Freed, "The form and function of questions in informal dyadic conversation," J. Pragmat., vol. 21, pp. 621-644, 1994.

[63] R. Gardner, On Some uses of the Conversational Token mm. The University of Melbourne, Australia: Unpublished PhD Thesis, 1995.

[64] S. C. Brown, P., \& Levinson, Politeness: Some universals in language usage. Cambridge, UK: University Press., 1987.

[65] W. Zhu, "Polite Requestive Strategies in Emails: An Investigation of Pragmatic Competence of Chinese EFL Learners," RELC J., vol. 43, no. 2, pp. 217-238, 2012.

[66] C. Levinson, Stephen, Pragmatics. Cambridge: Cambridge University Press, 1983.

[67] C. Roever and S. Al-gahtani, "The Development of ESL Proficiency and Pragmatic Performance," ELT Journal;, vol. 69, no. 4, pp. 395-404, 2015.

[68] D. Myhill and F. Dunkin, "Questioning Learning," Lang. Educ., vol. 19, no. 5, pp. 415-427, 2005.

[69] P. Black and D. Wiliam, "Classroom Assessment and Pedagogy," Assess. Educ. Princ. Policy Pract., vol. 25, no. 6, pp. 1-25, 2018.

[70] N. Taguchi, "The Effects of Practice Modality on Pragmatic Development in L2 Chinese," 2012.

[71] S. Eshghinejad and M. R. Moini, "Politeness Strategies Used in Text Messaging: Pragmatic Competence in an Asymmetrical Power Relation of Teacher - Student," vol. 2016, 2016. 